\title{
Long term oral acyclovir in disseminated mucocutaneous herpes simplex:
}

\author{
A case report
}

\section{A MINDEL \\ From the Academic Department of Genitourinary Medicine, Middlesex Hospital Medical School, London}

SUMMARY A 24 year old woman with Crohn's disease presented initially with a severe primary genital herpes infection. After the first attack frequent recurrences occurred on the hands, feet, and genitalia. The patient was treated with oral acyclovir for 12 weeks, during which time she had two brief minor recurrences. After treatment was stopped lesions recurred at the same sites.

\section{Introduction}

Genital herpes is a distressing, painful, and recurrent condition for which there was no effective treatment until recently. We describe a patient with genital herpes whose lesions disseminated to other cutaneous areas and whose disease was controlled by continuous oral acyclovir.

\section{Case report}

A 24 year old woman journalist was admitted to the Leeds Infirmary with a severe attack of primary genital herpes in mid May 1982. She also had longstanding Crohn's disease for which she had been taking azothiaprine $100 \mathrm{mg}$ daily and prednisolone $7 \cdot 5 \mathrm{mg}$ daily for 10 years. Her attack of herpes was first treated with topical idoxuridine for one week, with no effect, and she was therefore given a five day course of intravenous acyclovir $250 \mathrm{mg}$ eight hourly. By the end of this course the sores had healed, and she was discharged from hospital.

Five days after discharge she developed painful vesicles on the right middle finger, right heel, and the right fourth toe. The lesions persisted and when she was seen in the department of genitourinary medicine at the Middlesex Hospital on 23 June, a group of vesicles was noted on the radial aspect of the middle finger of the right hand and a similar crop were seen on the right heel, right fourth toe, and between the web spaces of the third and fourth right toes. Genital examination was normal. Herpes simplex virus type 2

Address for reprints: $\operatorname{Dr}$ A Mindel, James Pringle House, The Middlesex Hospital, London WIN 8AA

Accepted for publication 12 September 1983 was isolated from the finger, heel, and toe. The patient was advised to bathe the affected areas with saline, and all the lesions were healing when she was seen a week later.

In early July she enjoyed a week free of any lesions, but on 15 July vesicles appeared on the vulva and right toe and when she was examined on 22 July the cervix was also affected. The lesions had healed without treatment by the end of July, but there was a further recurrence a week later on the finger, heel, toe, vulva, and cervix. The patient was then given a twelve week course of oral acyclovir $200 \mathrm{mg}$ four times daily, and all lesions disappeared within five days. Two minor recurrences occurred during the treatment period (early September to mid October), one on the finger and one on the vulva; both lasted less than 12 hours, consisted of a single vesicle, and occurred 10-12 hours after the patient had missed a tablet. A week after treatment was stopped lesions recurred on the heel and toe, and within a few days the vulva, cervix, and finger were also affected. The figure shows the occurrence of lesions in relation to her treatment.

\section{Discussion}

Recurrent herpes infections may cause profound psychological and sexual dysfunction, and until recently little could be done to help patients with such infections. Acyclovir has been shown to decrease the length and severity of primary genital herpes, and of each recurrent attack, but not to prevent recurrences. ${ }^{1-7}$ There is no published report on the long term prophylactic use of acyclovir in genital herpes. This somewhat unusual case shows that continuous oral acyclovir can stop frequent recurrences during its use but has little effect on the 


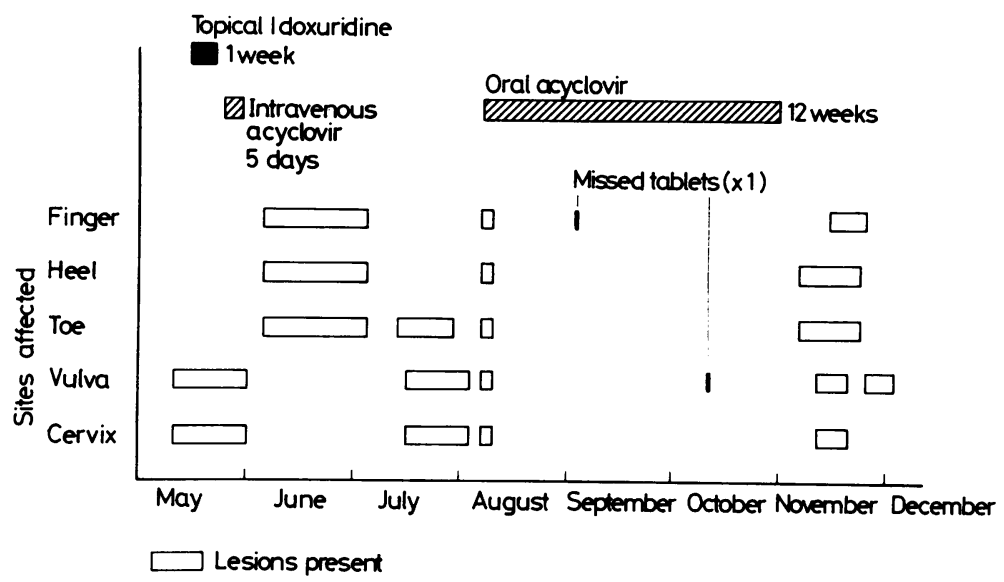

FIGURE Clinical course and treatment of a patient with disseminated herpes simplex.

long term pattern of the illness; and that unless the treatment is taken regularly rapid break through recurrences can occur.

The long term use of acyclovir does raise concern about drug resistance, ${ }^{89}$ toxicity, and dependency. Although continuous use would not seem to increase resistance, repeated courses of the drug may well do so. In the short term the drug has minimal toxicity; long term treatment will, however, require careful monitoring. Many of the patients will be women of child bearing potential, and the question of safety in pregnancy will also arise.

Finally, this case illustrates the potential problem of dependency. It is understandable that a patient should become dependent on a drug that can "switch off" a disease, which occurred in this case. Doctors should be aware that this can happen before they commit themselves and their patients to long term treatment. They should also balance the need to control disease against possible resistance and toxicity.

I thank Dr A P Fiddian of the Wellcome Research Laboratories, Beckenham for supplying the acyclovir.

\section{References}

1. Mindel A, Adler MW, Sutherland S, Fiddian AP. Intravenous acyclovir treatment for primary genital herpes. Lancet 1982 ; i:697-700.

2. Corey L, Fife $\mathrm{KH}$, Benedetti JK, et al. Intravenous acyclovir for the treatment of primary genital herpes. Ann Intern Med 1983;98:914-21.

3. Nilsen AE, Aasen T, Halsos AM, et al. Efficacy of oral acyclovir in the treatment of initial and recurrent genital herpes. Lancet 1982; ii:571-3.

4. Bryson YJ, Dillon M, Lovett $\mathbf{M}$, et al Treatment of first episode of genital herpes simplex virus infection with oral acyclovir. A randomised double-blind controlled trial in normal subjects. N Engl J Med 1983; 308:916-21.

5. Corey L, Nahmias AJ, Guinan ME, Benedotti JK, Critchlow CW, Holmes KK. Trial of topical acyclovir in genital herpes simplex infections. $N$ Engl J Med 1982; 306: 1313-9.

6. Thin RN, Nabarro JM, Davidson-Parker J, Fiddian AP. Topical acyclovir in the treatment of initial herpes. Br J Vener Dis 1983;59:116-9.

7. Fiddian AP, Kinghorn GR, Goldmeier D, et al. Topical acyclovir in the treatment of genital herpes: a comparison with systemic therapy. J Antimicrob Chemother 1983;12suppl B: $67-77$.

8. Field HJ. Development of clinical resistance to acyclovir in herpes simplex virus-infected mice receiving oral therapy. Antimicrob Agents Chemother 1982; 21:744-52.

9. Burns WH, Saral R, Santos WG, et al. Isolation and characterisation of resistance herpes simplex virus after acyclovir therapy. Lancet 1982; i:421-3. 